\title{
LOS PROCESOS DE “PRESUPUESTO PARTICIPATIVO" EN AMÉRICA LATINA: ÉXITO, FRACASO Y CAMBIO
}

\author{
BeNJAMIn GoldFrank \\ Universidad de Nuevo MÉxico, Estados Unidos
}

\begin{abstract}
Resumen
Este artículo examina intentos encaminados a introducir mecanismos de participación en el proceso del presupuesto en gobiernos locales. La hipótesis general es que el diseño y los resultados del presupuesto participativo (PP) dependen tanto de las intenciones de los diseñadores como de las condiciones previas del lugar específico, en especial, el grado de descentralización y la institucionalización de los partidos de oposición. Estos supuestos se examinan a través de una comparación controlada de Caracas, Montevideo y Porto Alegre, y, de forma más amplia, de las experiencias nacionales de Brasil, Bolivia, Guatemala, Nicaragua y Perú. Se concluye que las políticas nacionales de PP no han tenido un éxito generalizado que promueva la participación ciudadana a nivel local, la transparencia fiscal, ni gobiernos municipales eficientes.
\end{abstract}

Abstract

This article examines efforts at introducing participatory mechanisms into local government budget processes. The broad hypothesis advanced is that the design and, partially in turn, the results of participatory budgeting (PB) depend on both the designing actors" intentions and the pre-existing conditions in the particular locale, especially the degree of fiscal decentralization and the institutionalization of opposition parties. These hypotheses are examined through a controlled comparison of PB in three cities -Caracas, Montevideo, and Porto Alegre- and a broad comparison of Brazil, Bolivia, Guatemala, Nicaragua, and Peru. I conclude that national legal mandates for PB have not had widespread local success in encouraging citizen participation, fiscal transparency, and effective municipal government.

PALABRAS CLAVE • Presupuesto participativo • Gobiernos locales • Descentralización

- Transparencia • Democratización

\section{INTRODUCCIÓN}

De 1990 a 2005, el "presupuesto participativo" (PP) ha evolucionado de forma considerable ${ }^{1}$. Lo que alguna vez fue un poco conocido proceso de participación popular, impulsado por algunos partidos latinoamericanos de izquierda, como una forma de reinventar el socialismo, se ha convertido en una "buena práctica" dentro de la caja de herramientas de buen gobierno promulgada por instituciones internacionales de desarrollo. De acuerdo a qué tan rigurosa sea la definición de PP, éste se ha expandido de algunas docenas de ciudades, sobre todo en Brasil, a entre 250 y 2.500 lugares tan sólo en Latinoamérica. La cifra inicial incluye aquellas ciudades donde el PP comenzó como una iniciativa de gobiernos locales, en países desde México y la República 
Dominicana hasta Argentina y Chile. Las segundas cifras incluyen a los gobiernos municipales que, por leyes nacionales, han tenido que implementar consultas ciudadanas en cuanto a la organización del presupuesto, tales como Bolivia, 327 municipios; Nicaragua, 125 municipios; y Perú con 1.821 distritos, 194 provincias y 25 regiones. Las interpretaciones de PP abundan, especialmente, sobre aquel practicado en Porto Alegre, ciudad brasileña que le dio nombre y lo publicitó. Sin embargo, los estudios acerca de cómo es conducido el PP, especialmente fuera de Brasil, son escasos. Y los trabajos comparativos entre las diferentes maneras en las que el PP es diseñado e implementado han sido excepcionales.

Este artículo examina intentos encaminados a introducir mecanismos de participación en el proceso del presupuesto en gobiernos locales. Tras una breve definición de PP y una descripción de su historia, se presentan varias perspectivas normativas y analíticas. La hipótesis general es que el diseño y los resultados de PP dependen tanto de las intenciones de los diseñadores como de las condiciones previas del lugar específico, en especial, el grado de descentralización y la institucionalización de los partidos de oposición. Las siguientes secciones examinan estas hipótesis a través de una comparación controlada de tres ciudades: Caracas, Montevideo y Porto Alegre. A su vez, de forma más amplia, se comparan las experiencias nacionales de Brasil, Bolivia, Guatemala, Nicaragua y Perú. En este sentido, se sostiene que las políticas nacionales de PP no han tenido un éxito generalizado que promueva la participación ciudadana a nivel local, la transparencia fiscal, ni gobiernos municipales eficientes. Este fracaso se debe, en parte, a que los diseñadores de las leyes nacionales tuvieron otros objetivos y, también, a los obstáculos locales, incluyendo alcaldes reacios, baja capacidad fiscal y administrativa de los gobiernos municipales, y sociedades civiles fragmentadas y conflictivas.

\section{DEFINICIONES E HISTORIA DEL PRESUPUESTO PARTICIPATIVO MÁS ALLÁ DE PORTO ALEGRE}

Se han ofrecido definiciones generales y particulares acerca de presupuesto participativo. Las definiciones generales describen al PP como un proceso a través del cual los ciudadanos pueden contribuir en la toma de decisiones acerca del presupuesto gubernamental. Las definiciones particulares generalmente se derivan de la experiencia de PP en Porto Alegre y hacen énfasis en varias características: el proceso está abierto a cualquier individuo que desee participar, combina democracia participativa y representativa, implica deliberación (no sólo consulta), busca la redistribución, y se autorregula, en la medida en que los participantes ayudan a definir las reglas que rigen el proceso. Ni las definiciones generales ni las particulares son referentes ideales para la reconstrucción de la historia de PP. Las definiciones generales abordarían muchos casos, incluyendo "lobbying" y cabildos abiertos generales; las definiciones específicas incluirían muy pocos. Una definición más útil es que el PP es un proceso a través del cual los ciudadanos, de forma individual o por medio de organizaciones cívicas, pueden de forma voluntaria y constante contribuir en la toma de decisiones del presupuesto público, a través de una serie de reuniones anuales con las autoridades gubernamentales. Esta última definición es la que se usa en este trabajo y en la siguiente descripción de la historia de PP. 
En la mayor parte de lo escrito acerca del tema, el PP se presenta como una invención del Partido de los Trabajadores (PT) en Porto Alegre, durante 1989. Sin embargo, sus orígenes son más complejos. Existen varios casos, al final de la década del setenta y comienzos de la del ochenta, en donde gobiernos municipales, bajo el control del Partido del Movimiento Democrático Brasileño (PMDB), sometían sus presupuestos al debate público, incluido Lages, Bõa Esperanza y Pelotas, donde un ex alcalde sostiene haber inventado el PP (Goldfrank y Schneider, 2006). Además, el PT experimentó variaciones del PP en varios de los 36 municipios donde ganó las elecciones de 1988 (Abres, 1996). Por otra parte, el diseño particular de PP en Porto Alegre fue el resultado de la combinación entre asociaciones vecinales y la administración municipal del PT. Por lo menos otros dos partidos de izquierda implementaron programas de PP casi al mismo tiempo que el PT en Brasil: uno fue La Causa R (CR) en Ciudad Guayana (y poco después en Caracas), Venezuela, y el otro fue el Frente Amplio (FA) en Montevideo, Uruguay. En 1990, el proceso de Porto Alegre fue conocido como "presupuesto participativo". Tanto el nombre como su práctica (aunque modificada) fueron adoptados en otras ciudades petistas después de 1992 y, desde 1996, se extendió a varios gobiernos locales latinoamericanos, cuando la Conferencia Habitat II de la ONU reconoció al PP de Porto Alegre como una de las 42 mejores prácticas de gobierno urbano.

Los primeros experimentos de PP tuvieron en común el ser implementados en gobiernos locales por partidos opuestos al gobierno nacional ${ }^{2}$. Los experimentos de PP se dieron en ciudades brasileñas, en gran medida, porque Brasil era el único país bajo dictadura -y uno de los únicos países en la región- que simultáneamente permitía la existencia de un partido de oposición, daba significativas responsabilidades de gasto a los municipios y mantenía elecciones municipales (excepto en ciudades estratégicas como las capitales de estado y puertos principales). Las tendencias paralelas de descentralización y democratización que se dieron en Latinoamérica durante las décadas de 1980 y 1990 estimularon experiencias similares dentro y fuera de Brasil, especialmente donde los partidos de izquierda estaban aliados con movimientos sociales que demandaban tanto democracia como mejoras en los servicios urbanos.

De forma distinta, muchas de las experiencias posteriores de PP, que generalmente no adoptaron este nombre, fueron implementadas por partidos en el poder nacional de tendencia de centro 0 de derecha. Ejemplo de este caso fue la Ley de Participación Popular en Bolivia, impulsada por el presidente Sánchez de Losada, o las reformas municipales de Nicaragua, al final de la década de 1990, bajo el gobierno del presidente Alemán, como también las reformas de descentralización en Guatemala propuestas bajo los acuerdos de paz de 1996 y promulgadas en 2002 bajo el presidente Portillo. En los tres casos, los requisitos de participación ciudadana, necesarios para recibir fondos de alivio para la deuda, bajo el programa de HIPC II (Highly Indebted Poor Countries), que comenzó en 2000, parecen haber estimulado los esfuerzos para asegurar la implementación de leyes nacionales por parte de los municipios. La Ley de Presupuesto Participativo de Perú en 2003 se da de forma diferente, ya que utiliza el nombre de PP, y se promueve bajo un presidente supuestamente de centro izquierda: Toledo. Dentro de Brasil, la mayoría de experiencias recientes de PP se han dado en administraciones de izquierda, en especial, aquellas del Partido de los Trabajadores. Sin embargo, varios partidos de distintas tendencias han buscado su implementación. El PP ya no es más un proyecto exclusivo de la izquierda, a pesar de sus

2 Para uno de los primeros artículos informando sobre la expansión de experimentos de la izquierda en gobiernos locales en América Latina, ver Fox (1995). 
orígenes ideológicos. De hecho, desde sus comienzos, el PP ha generado un amplio espectro de interpretaciones ideológicas, que podemos Ilamar: las de la nueva izquierda, las liberales, las ortodoxas y las conservadoras.

Los primeros en proponer el PP fueron partidos de la nueva izquierda, tal como el PT de Brasil, el FA de Uruguay y la CR de Venezuela. Estos hacían parte de la izquierda renovada y postautoritaria que abogaba por la profundización de la democracia a través de la participación popular. Estos partidos vieron en el PP una estrategia que ayudaba a la relegitimación del Estado de cara a los ataques neoliberales. El objetivo era la consolidación de un Estado controlado por los ciudadanos, a través del PP, que fuera efectivo, transparente, y que abogara por la redistribución. Para algunos con esta visión, como Olivio Dutra, primer alcalde petista en Porto Alegre, el PP también creaba conciencia socialista y el potencial para una hegemonía alternativa (Dutra, 2002: 5-6).

La aproximación liberal al PP puede ser vista en sitios web como los del Banco Mundial y otras instituciones financieras internacionales (IFI), así también en las leyes de PP de Bolivia, Nicaragua y Guatemala, que las IFI ayudaron a diseñar. Los liberales compartían las esperanzas de la nueva izquierda en cuanto a la reducción de la pobreza, el fin de la corrupción y el clientelismo; pero, a su vez, su aproximación veía al PP como una estrategia coexistente con otras reformas que reducen el rol estatal (Campbell, 2003). La visión de los liberales acerca del PP lo asumía más como una consulta que como una deliberación, e incluso como una fuente de trabajos y recursos voluntarios y el pago de impuestos.

La izquierda ortodoxa, incluido el líder aymara de Bolivia, Felipe Quispe, así como algunas facciones del PT y ex petistas, están de acuerdo con los liberales hasta cierto punto. Todos ven al PP como un recurso que favorece el desarrollo capitalista, pues éste ayuda a estabilizar la democracia, al estimular la confianza ciudadana en el gobierno. Para la izquierda ortodoxa, el PP, por ende, ayuda a la burguesía a manejar la crisis del capitalismo y, por lo tanto, socava la revolución.

Los conservadores ven al PP como antidemocrático y turbulento. Varios partidos políticos establecidos critican al PP, pues ven en él un riesgo para la democracia representativa, ya que permite que voluntarios no representativos ostenten más poder que los concejales y otros profesionales del gobierno mejor calificados. Por lo tanto, el PP afecta la legitimidad de las cámaras municipales y conduce a una pobre prestación de servicios. Además, los participantes del PP son manipulados por el partido gobernante local, haciéndoles creer que ellos tienen poder en la toma de decisiones. Los conservadores usan estos argumentos contradictorios para asociar al PP con totalitarismo, en cuanto el PP es un poder paralelo, que reemplazará la democracia multipartidista y el capitalismo por un partido socialista único. Lo que esta revisión de aproximaciones normativas demuestra es que el PP no es un instrumento técnico neutral, como muchas IFls lo sugieren, al presentar al PP como parte de la "caja de herramientas" para el desarrollo.

\section{CLAVES PARA EL ÉXITO: CONDICIONES PREVIAS O DISEÑO INSTITUCIONAL}

La mayoría de los escritos acerca de los experimentos de PP no ha dado una respuesta satisfactoria con respeto a por qué algunos de éstos fallan, mientras que otros tienen éxito. En cambio, su interés ha sido demostrar cómo el PP recoge conceptos como "participatory publics" (Wampler y Avritzer, 2004), desarrollo deliberativo (Evans, 2004) o gobierno de empoderamiento participativo (Fung 
y Wright, 2001), entre otros ${ }^{3}$. Éstos y otros académicos han hecho interesantes análisis acerca de PP, enfocándose casi en su totalidad en la experiencia brasileña, sobre todo en la experiencia exitosa de Porto Alegre. Ellos han demostrado que el PP puede conseguir muchos de los objetivos de la profundización de la democracia, en especial, en cuanto a que redirigen recursos públicos hacia los barrios más pobres (Marquetti 2002), extienden la prestación de servicios (Sousa Santos, 1998), democratizan las organizaciones civiles existentes e incentivan la creación de nuevas (Abers, 2000; Baiocchi, 2001), incrementan la transparencia y “accountability” (Wampler, 2004), mientras que reducen el clientelismo (Abers, 2000), y aumentan la representación democrática de los tradicionalmente excluidos (Nylen, 2003). Estos investigadores también demuestran que estos resultados alentadores no están garantizados por la implementación del PP, y que incluso casos ejemplares muestran resultados contradictorios (Baierle, 2003).

Para explicar el éxito o fracaso de los distintos experimentos de PP, los académicos proponen una serie de características de diseño institucional y las condiciones previas favorables. La lista a continuación sintetiza los factores relevantes que potencialmente facilitan la implementación exitosa del PP:

\section{Condiciones previas}

A. Voluntad política: el partido involucrado y, en especial, el alcalde y los oficiales encargados de llevar a cabo el PP deben estar comprometidos ideológicamente con la apertura de canales que permitan la participación ciudadana con miras a compartir la toma de decisiones.

B. Capital social: la comunidad local debe tener asociaciones civiles, preferiblemente dispuestas a participar en los asuntos municipales.

C. Personal competente: La administración municipal debe contar con empleados técnicamente calificados.

D. Tamaño reducido: el municipio, o al menos el distrito usado para la toma de decisiones, no debe ser tan grande que desaliente la acción colectiva.

E. Recursos suficientes: los gobiernos municipales deben contar con los fondos suficientes para la ejecución de proyectos públicos y programas sociales.

F. Plataforma legal: las leyes existentes deben permitir y preferiblemente incentivar la participación ciudadana en cuanto a las decisiones presupuestarias.

G. Descentralización política: los alcaldes y concejales deben haber sido electos por medio de procesos democráticos.

La mayoría de los académicos sostiene que la voluntad política ${ }^{4}$, los recursos suficientes y la descentralización, son elementos necesarios para el éxito del PP, y muchos incluyen el factor de

3 Por razones de espacio no es posible incluir todos los trabajos relevantes acerca del PP. Para una revisión bibliográfica acerca del PP en Brasil, ver Souza (2001).

$4 \quad$ El concepto de voluntad política, tanto en relación a las posibilidades del éxito del PP como en la ciencia política generalmente, es muchas veces poco explícito y de difícil operacionalización. En este trabajo se usa con énfasis en el compromiso ideológico implicado, reconociendo que partidos y líderes pueden tener muchas motivaciones por su acción política. 
Ias asociaciones civiles, mientras que consideran a las otras condiciones como favorables, pero no requeridas. Existe menos consenso en cuanto a cuáles son las características más importantes de diseño institucional, e incluso si algunas de ellas favorecen o afectan negativamente al PP.

\section{Diseño institucional}

A. Enfoque de necesidades inmediatas vs. planeación a largo plazo: algunos sostienen que una clave del éxito en el PP es enfocar las discusiones en un rango amplio de necesidades prácticas e inmediatas; otros, que este enfoque socava el debate acerca de temas más trascendentales y con efectos a largo plazo.

B. Informal vs. formal: algunos favorecen darle al PP una estructura informal y abierta, que permita la participación de individuos o grupos sin dar privilegios a organizaciones ya existentes, y que pueda ser modificada por los mismos participantes; otros plantean que, para evitar la manipulación política del PP por parte de los partidos en el poder y para garantizar la representación de actores políticos y sociales importantes, el PP debe estar formalizado por ley.

C. Deliberación: los participantes deben enfrentar discusiones cara a cara y deben contar con poder de decisión acerca del proceso de presupuesto, al menos en cuanto a priorizar las inversiones por realizar.

D. Supervisión centralizada: la alcaldía debe estar directamente involucrada en la coordinación del proceso de PP.

E. Reglas e información asequibles: las reglas, incluyendo los criterios para asignar recursos en los barrios y la información presupuestaria, deben estar disponibles y accesibles para el público en general.

Al menos tres vacíos permanecen sin llenar en la discusión acerca de PP. Uno es la falta de una rigurosa comparación entre los distintos modelos de PP experimentados en diferentes países, que permita identificar cuáles son las características de diseño y las condiciones previas que conducen al éxito 0 al fracaso. Otro vacío es el hecho de que el diseño de PP y las condiciones bajo las cuales se introduce no han sido relacionadas teóricamente. Tercero, los aspectos competitivos del PP no han sido profundamente examinados, en especial, el tema del rol de los partidos de oposición. La siguiente sección aborda estos tres temas mediante una comparación estructurada de experiencias de PP en Caracas, Montevideo y Porto Alegre.

\section{HISTORIA DE TRES CIUDADES ${ }^{5}$}

En este apartado se comparan experiencias de PP que en un inicio fueron similares, pero que eventualmente condujeron a resultados diferentes. Cada una de estas experiencias fue liderada por un partido de izquierda que llegó a la alcaldía por primera vez, prometiendo reformas participativas que profundizaran la democracia: el FA en Montevideo, 1990 hasta hoy día; el PT en Porto Alegre, 
1989-2004; y CR en Libertador, el municipio más grande en el área metropolitana de Caracas ${ }^{6}$, 1993-19957. Las reformas principales crearon nuevas instituciones dándole a los ciudadanos la oportunidad de influir en las decisiones de gasto gubernamental, pero sus ambiciones eran mayores: revitalizar el papel de la ciudadanía, abrir la administración local al escrutinio público y responder a los requerimientos de servicios desatendidos. Sólo Porto Alegre consiguió cada objetivo. La experiencia de Caracas falló en cuanto al compromiso ciudadano y la respuesta gubernamental, aunque mejoró la transparencia administrativa. Las nuevas instituciones participativas en Montevideo ayudaron a la transparencia y a la prestación de servicios (e incluso a aumentar la popularidad del alcalde, quien más tarde llegó a la presidencia), pero no generó un activismo ciudadano sostenido ni amplio. ¿Cuál es la explicación de la diferencia de resultados?

En esta investigación se determinó que, aunque los tres casos comparten caracaterísticas identificadas por los académicos como factores de potencial éxito, tales como voluntad política, el nivel de capital social, el tamaño de las ciudades, la competencia del personal y la supervisión centralizada, éstos difieren en dos aspectos clave: tanto el grado de descentralización de la autoridad y los recursos a los gobiernos locales como el nivel de institucionalización de los partidos de oposición. Estas condiciones afectaron la posibilidad de que los partidos izquierdistas de turno diseñaran instituciones participativas efectivas que podrían incentivar un compromiso ciudadano a largo plazo. Sólo los gobiernos de Porto Alegre y de Montevideo tuvieron esta posibilidad, pues sólo en Brasil y Uruguay el gobierno central había otorgado suficientes recursos y autonomía jurídica a los gobiernos locales. Y fue en Porto Alegre, en un contexto de débil institucionalización de los partidos de oposición, que la democracia se profundizó más. Allí las organizaciones comunitarias autónomas presionaron al PT hacia el diseño de un programa de participación abierta, que permitiera a los ciudadanos ser incluidos en la toma de decisiones. De forma opuesta, la fuerte institucionalización de los partidos de oposición en Montevideo y Caracas entorpecieron los programas de participación frenteamplista y causaerrista, forzando cambios que abogaban por un diseño más formalizado y restrictivo, respectivamente, en los cuales el aporte ciudadano estaba limitado y subordinado a las estructuras formales de los partidos dominantes.

Los experimentos de PP aparecieron de igual manera a comienzos de la década de 1990. Los nuevos partidos de turno comenzaron por dividir la ciudad en distritos con sus respectivas asambleas públicas: 19 en Caracas, 18 en Montevideo y 16 en Porto Alegre. En estas asambleas, se animó a los ciudadanos a hacer demandas directas a la rama ejecutiva, pasando por encima de la cámara municipal, donde la oposición era conspicua. El primer año, cientos y a veces miles de ciudadanos identificaron y priorizaron obras públicas para que fueran tenidas en cuenta en el presupuesto de inversión anual. En cada ciudad, las nuevas instituciones eventualmente incluyeron asambleas populares de participación directa y voluntaria, e hicieron más frecuentes pequeños foros a nivel distrital, cuyos representantes eran elegidos a través de procedimientos establecidos. A primera vista, estos programas tuvieron una notoria semejanza. Sin embargo, con el paso de los años,

6 A menos que se indique algo distinto, las referencias a Caracas indican el Municipio Libertador, conocido como Alcaldía de Caracas.

7 Los datos, recolectados durante quince meses de trabajo de campo, incluyen entrevistas con representantes gubernamentales y del partido, líderes de oposición y líderes comunitarios, encuestas en Montevideo y Porto Alegre; observaciones de más de 100 reuniones, documentos gubernamentales, y reportes de prensa. 
los índices de participación en Porto Alegre aumentaron, presagiando su futuro éxito, mientras que los índices de Montevideo se mantuvieron y los de Caracas disminuyeron.

La voluntad política de los partidos de turno no explica esta divergencia. Como se mencionó, tanto la CR, el FA y el PT eran ejemplos de la transformación ideológica de gran parte de la izquierda latinoamericana. Cada uno de los alcaldes demostró dedicación personal, al asistir a las asambleas por toda la ciudad. Estos partidos tenían también varios factores en común: estaban integrados por distintas facciones de tendencias políticas diversas; una afiliación basada en movimientos sindicales y comunitarios; la mayoría de sus votantes pertenecía a la clase media y trabajadora; no tenían experiencia gubernamental, y habían llegado al poder local por una escasa pluralidad más por votos de castigo en contra de los políticos nacionales que por votos de apoyo a las reformas participativas. Por lo tanto, ninguno de los partidos tuvo ventajas "inherentes" que favorecieran la implementación de programas participativos.

En cada ciudad, el nivel de capital social fue también similar, con cientos de asociaciones vecinales y otras organizaciones comunitarias creadas en la década de 1970 y a principios de la de 1980, que posteriormente enfrentaron un decrecimiento, reflejando el patrón de surgimiento y caída que los académicos de Brasil, Venezuela y Uruguay han analizado de forma separada en términos de "ciclos de protesta". A pesar del último periodo de decaimiento, cientos de asociaciones vecinales fueron registradas en cada ciudad en el tiempo en que comenzó el PP: 427 en Caracas durante 1994; 300 en Porto Alegre en 1988, y 626 en Montevideo en 1988, de las cuales 436 continuaban funcionando (Goldfrank, 2002: 75). También aparecieron docenas de cooperativas, ollas comunes, clubes de madres y grupos culturales, y surgieron federaciones de asociaciones con el objetivo de coordinar demandas por servicios públicos y reformas participativas: FACUR (Caracas), MOVEMO (Montevideo) y UAMPA (Porto Alegre). Cada ciudad contó con una sociedad civil relativamente organizada, aunque no tan dinámica como en el pasado. Estos grupos populares tenían diversas perspectivas políticas, en especial, con respecto a su afiliación con los diferentes partidos. Algunos mantenían lazos ideológicos o clientelistas con partidos particulares, mientras otros rechazaban cualquier tipo de relación con éstos. La combinación específica difería entre las distintas ciudades, pero en formas relacionadas con el tipo de los partidos locales que hubieran sido históricamente predominantes (ver a continuación).

Junto al parecido de los partidos gobernantes y la sociedad civil, estas ciudades también desplegaron desigualdades profundas a comienzos de los noventa. Las diferencias geográficas reforzaron estratificaciones étnicas y de clase, dividiendo a los ciudadanos en distintos niveles de valor. En cada ciudad, la categorización binaria de barrios -entre formales e informales- está fuertemente arraigada y señala una importante división social. Tal bifurcación se relaciona con patrones de desarrollo similares. El crecimiento acelerado de la población de mediados de siglo disminuyó en la década de 1970, cuando las áreas centrales empezaron a perder población en relación con las zonas periféricas menos desarrolladas. Este crecimiento centrífugo generó dificultades en los gobiernos municipales, por causa del patrón de prestación de servicios anterior, que se concentraban en los centros urbanos formales e ignoraban los asentamientos ilegales de la periferia. A finales de la década de 1980, estos patrones tuvieron como efecto que un amplio sector de los habitantes de estas zonas reclamara mejoras de infraestructura urbana, 0 la inclusión en la "ciudad legal". La gran mayoría de habitantes disponía de servicios esenciales, 
como agua y energía. Sin embargo, la prestación de éstos se daba en muchos casos por medios "informales" y poco confiables. Otros servicios básicos, como la pavimentación de las calles, la recolección de basuras, el transporte y la iluminación pública, tenían serias deficiencias. Una considerable minoría de los habitantes de cada ciudad vivía bajo condiciones de pobreza y las tasas de desempleo habían aumentado.

Finalmente, las burocracias de estas ciudades hacían parte del modelo patrimonial operante en la mayoría de las ciudades latinoamericanas: la nómina inflada, la ineficiencia, la corrupción mezquina y el precario mantenimiento de las instalaciones públicas afectaban a cada administración. En Porto Alegre, la nueva administración petista se quejó por el caso de 4.000 empleados "fantasmas" que nunca trabajaron. La CR y el FA hicieron acusaciones similares. Muchos trabajadores municipales vieron con desconfianza a las propuestas de reformas; otros se resistieron a ellas. Varios de los empleados municipales portoalegrenses "intentaron poner freno a la nueva administración" al retrasar deliberadamente los procedimientos administrativos (Schabbach, 1995: 85-86). En Caracas y Montevideo, muchos trabajadores municipales se negaron a realizar labores que no estuvieran incluidas en sus rígidas designaciones laborales. En el departamento de mantenimiento de Caracas, algunos empleados sólo lavaban pisos, otros sólo ventanas.

En suma, cada ciudad experimentó un nuevo partido de izquierda en el poder, que por medio del PP intentaba comprobar sus convicciones democráticas, expandir su base y atraer a sus aliados en los movimientos comunitarios disconformes con la inequidad, la mala prestación de servicios y gobiernos que no respondían a sus reclamos. Sin embargo, la creación paralela de instituciones participativas no generó resultados paralelos por dos diferencias cruciales.

\section{DESCENTRALIZACIÓN NACIONAL E INSTITUCIONALIZACIÓN DE PARTIDOS LOCALES DE OPOSICIÓN}

Los gobiernos centrales de Venezuela, Uruguay y Brasil asumieron reformas de descentralización durante las décadas de 1980 y 1990, al incrementar la autoridad fiscal, administrativa y política de los gobiernos locales. Sin embargo, los gobiernos locales de Brasil y Uruguay históricamente disfrutaron de mayores recursos y responsabilidades que aquellos de Venezuela, y las reformas brasileñas avanzaron más.

Hasta 1988, Venezuela era extremadamente centralizada. La administración nacional controlaba la mayoría de los recursos, proveía casi la totalidad de los servicios públicos y designaba a los gobernadores estatales. Las reformas de descentralización de 1988/1989 establecieron la elección directa de alcaldes, mayores transferencias de los recursos federales y responsabilidades nuevas (pero compartidas) a los gobiernos subnacionales. Las nuevas reformas de participación ciudadana fueron introducidas por medio de la creación de distritos (llamados parroquias) con representantes elegidos que servían como intermediarios entre las organizaciones comunitarias y los alcaldes. Sin embargo, en la práctica, los recursos municipales aumentaron muy modestamente (de 4,2\% del total de los recursos gubernamentales en 1989 al 5,7\% en 1993), y el gobierno central siguió prestando la mayoría de los servicios en la mayoría de ciudades (Mascareño, 2000: 66; 62-63). La alcaldía de Caracas ganó poco. 
Con una fuerte tradición federal que data de 1989, Brasil cuenta con una larga historia de fuerte descentralización en comparación a Venezuela. La Constitución brasileña de 1988 garantizaba tasas más altas de transferencias directas, más fuentes de recursos propios, como mayor responsabilidad en los servicios, y garantizaba la autonomía a los municipios. Estos casi duplicaron su porción de recursos gubernamentales después de 1988 (Montero, 2000: 65). Las cláusulas de autonomía permitían a los municipios la creación de leyes orgánicas que no estaban sujetas a la aprobación estatal o federal. En Porto Alegre, los recursos municipales aumentaron en un 82\% desde 1988 a 1992 (Goldfrank, 2002: 91).

Uruguay, caso único en Iberoamérica, tiene sólo dos niveles de gobierno: el gobierno central y 19 gobiernos provinciales, conocidos como departamentos y liderados por intendentes. Los departamentos tienen una larga tradición de recaudar impuestos, prestar servicios y funcionar como bastiones para la oposición política. Después de la dictadura militar, cuando los intendentes fueron designados y se redujo la autonomía fiscal, Uruguay volvió a intendentes elegidos, transfirió responsabilidades a los departamentos y aumentó los recursos departamentales. Sin embargo, el gobierno central mantuvo el poder de invalidar medidas de recaudación de impuestos, y negaba a Montevideo la ayuda fiscal que ofrecía a otros departamentos.

Los diferentes procesos nacionales de descentralización condujeron a una variedad de competencias de las alcaldías de Caracas, Montevideo y Porto Alegre. La figura 1 compara el presupuesto promedio anual per cápita en dólares corrientes de cada ciudad y el alcance de la jurisdicción sobre la prestación de servicios públicos, durante el primer mandato. La figura tiene limitaciones por causa de las fluctuaciones rápidas de las tasas de cambio en cada país y de las dificultades en comparar el valor real de la moneda en cada ciudad. Aun así la figura da una idea general de las diferencias. Comparadas con la alcaldía de Caracas, las administraciones de Porto Alegre y Montevideo pudieron gastar aproximadamente el doble de recursos por persona cada año. Estos dos gobiernos tuvieron también una responsabilidad mucho mayor sobre los servicios públicos, incluida una responsabilidad compartida sobre la vivienda pública, alcantarillado y agua.

En Caracas, la alcaldía carecía de la jurisdicción y recursos que le permitieran atender las necesidades más importantes de los ciudadanos. La CR intentó superar estas limitaciones al invitar a entidades de prestación de servicios de otros niveles de gobierno a sus programas participativos. Sin embargo, dado que estas entidades no estaban comprometidas con el proyecto de la CR, los participantes no pudieron convencerlas de prestarles atención. Por lo tanto, el diseño del programa en Caracas sólo podía abordar un rango limitado de temas en los que los ciudadanos realmente pudieran influenciar. Además, las arcas vacías de la alcaldía hacían muy difícil responder a las demandas ciudadanas, lo que tuvo como consecuencia la reducción en el poder de participación.

Por el contrario, en Montevideo y Porto Alegre, el FA y el PT se beneficiaron de una jurisdicción más amplia y un presupuesto mayor. Esta combinación fue clave, pues significó que el diseño de los programas participativos pudiera teóricamente permitir las propuestas de los participantes sobre un amplio espectro de temas, y que los gobiernos municipales contaran con los recursos para llevarlas a cabo. Tal diseño podría darles a los participantes un poder real. Esto fue lo que, en efecto, sucedió en Porto Alegre, pero no en Montevideo. La descentralización tiene mucho que ver en la explicación de los resultados, pero no da cuenta de las diferencias entre Porto Alegre 
FIGURA 1: Indicadores de descentralización

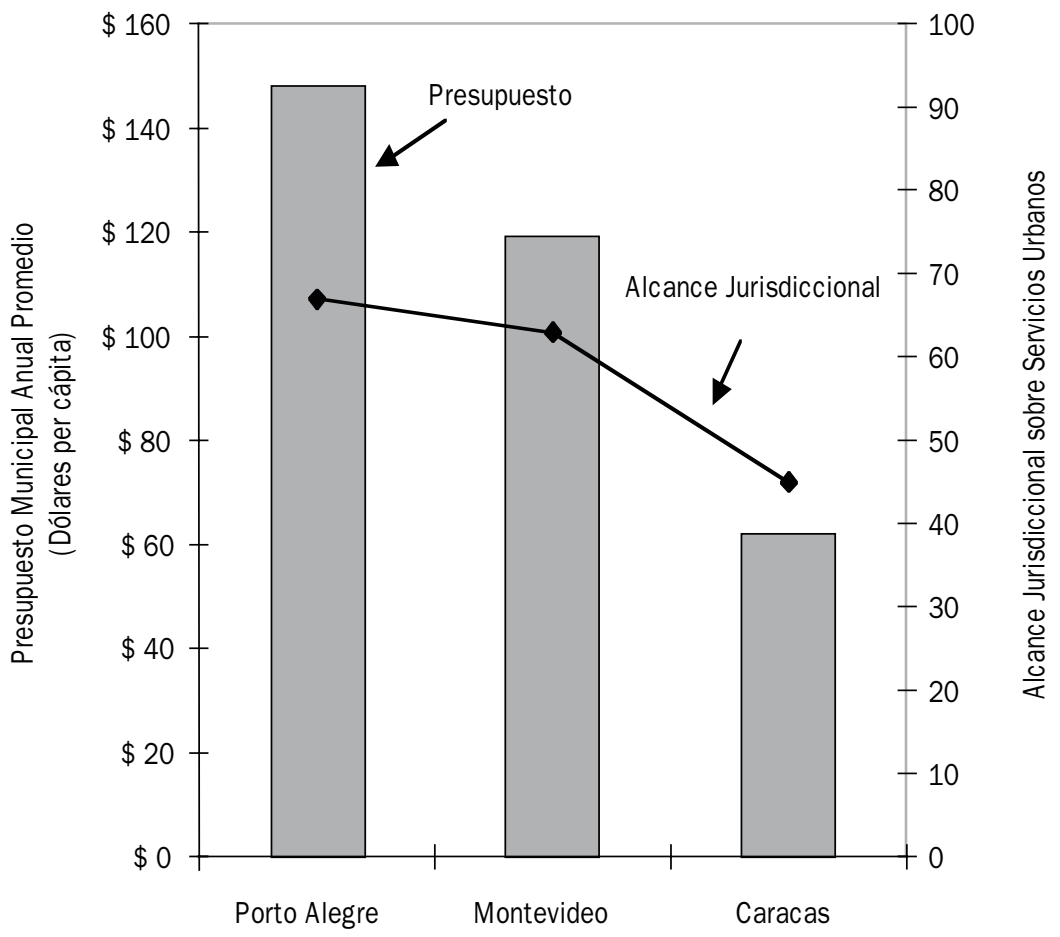

Fuente: Goldfrank 2002: 97, Figura 2.3. Para medir alcance jurisdiccional, se examinaron 25 servicios provistos por al menos uno de los gobiernos municipales y se clasificaron usando una escala de 0 a 4 , con 0 representando que no había un papel municipal y 4 representando responsabilidad municipal de facto y de jure.

y Montevideo. Es allí que el rol de la institucionalización de los partidos de oposición adquiere relevancia.

El concepto aquí empleado es tomado de las consideraciones originales de Huntington (1968) y adaptaciones (Kreuzer y Pettai, 2004). Generalmente se considera que los partidos son más institucionalizados en la medida en que generen lazos de lealtad entre sus miembros, votantes y grupos de interés, y consigan una mayor complejidad organizacional (con múltiples unidades territoriales o funcionales, interacciones regulares y liderazgos múltiples). La longevidad de los partidos refleja y refuerza la institucionalización. La mayoría de estudios de institucionalización de los mismos se centra en partidos de turno o sistemas de ellos; el interés, en este artículo, son los de oposición a nivel local. Los sistemas de partidos nacionales fueron ampliamente reflejados en Caracas, Montevideo y Porto Alegre, con dos grupos fuertemente institucionalizados en las primeras ciudades y muchos otros emergentes (o "inchoate") en Porto Alegre. Sin embargo, los partidos de turno locales no se adaptaban a este modelo. Al momento de llegar al poder local, la CR, el FA y el PT estaban débilmente institucionalizados, aunque los primeros dos estaban menos institucionalizados que sus rivales, mientras el PT lo estaba un poco más. 
Aún más importante es que los nuevos partidos de turno en Montevideo y Caracas enfrentaron a dos de ellos históricamente dominantes con raíces en los primeros años de los siglos XIX y XX respectivamente, que habían desarrollado redes clientelistas, una amplia identificación partidista entre los miembros y los votantes, y una costumbre de repartir el poder que excluía a los adversarios. Los partidos históricos habían perdido la alcaldía, pero mantenían varios concejales con fuertes lazos con los burócratas municipales, organizaciones comunitarias y poderosos líderes nacionales. En Porto Alegre, en contraste, el PT era sólo un partido más entre varios débilmente institucionalizados. No existían grupos históricamente dominantes, sino varios de ellos fundados durante la última década, que mostraban poca coherencia o disciplina interna. Estos no habían establecido aún lazos entre ellos o relaciones durables con los votantes, asociaciones civiles 0 empleados municipales.

Las diferencias en cuanto a la institucionalización de los partidos significó que, cuando la CR o el FA intentaron introducir programas de participación, sus oponentes tenían más que perder que los rivales del PT, y más armas a su disposición. La resistencia de los grupos de oposición fue, por lo tanto, mucho más fuerte en Caracas y en Montevideo, y no permitió que la CR y el FA pudieran diseñar ese tipo de programas que originalmente habían planeado. La reacción de las organizaciones de oposición en Porto Alegre fue comparativamente tímida, dándole al PT mayor libertad en el diseño del presupuesto participativo. Otra de las consecuencias de una oposición débilmente institucionalizada fue que las organizaciones comunitarias portoalegrenses gozaran de mayor autonomía frente a las agrupaciones políticas. Los distritos mejor organizados lucharon constantemente por un programa de participación efectiva, que les otorgara un mayor poder en la toma de decisiones sobre un amplio espectro de temas. En contraste, muchos grupos comunitarios caraqueños tenían lazos con los partidos rivales e intentaron sabotear el programa participativo de la CR. Estas lealtades de grupo en Montevideo se dividían entre el FA y la oposición, por lo que la participación fue tímidamente apoyada o rechazada.

\section{Caracas}

No es que los rivales de la CR en Caracas estaban institucionalizados. Desde la década de 1960, Acción Democrática (AD) y Copei dominaban completamente las arenas política y social, llevando a los académicos a calificar a Venezuela como una "partidocracia" (Coppedge, 1994). AD particularmente tenía una fuerte relación con los sindicatos, y los miembros del partido superaban los dos millones en 1985 (Coppedge, 1994: 29). La dominación de AD se extendía sobre Caracas. AD ganó la primera elección municipal con Claudio Fermín, quien estrechó los lazos con los sindicatos municipales y las asociaciones vecinales. Una nueva federación municipal (Favemli), por ejemplo, tenía un presidente perteneciente a la AD y casi 300 asociaciones miembros. Cuando en 1992, la CR venció por poco a AD en las elecciones municipales de Caracas, AD tenía muchos recursos a su disposición, desde asociaciones vecinales a sindicatos con sus miembros leales. Durante los siguientes tres años, AD dio una batalla por retomar el poder en Caracas. Esta batalla tomó diferentes formas y planteó restricciones severas en la habilidad de la CR para diseñar e implementar su programa de participación, llamado gobierno parroquial.

Los sindicatos municipales relacionados con AD constantemente protestaban, comenzando con un paro de un mes de duración, que retrasaban los contratos de obras públicas. Lo trabajadores también recurrieron al sabotaje, destruyendo registros públicos y computadores, y al robo, 
incluyendo ruedas de los autobuses municipales. Dado el control de AD sobre los sindicatos y cortes laborales, el alcalde Aristóbulo Istúriz tenía mucha dificultad para despedir trabajadores. Le tomó a Istúriz casi un año echar a un empleado que lo había asaltado. El otro principal aliado de $A D$, las asociaciones vecinales, se unieron al ataque, rechazando participar en las reuniones de gobierno parroquial o interrumpiéndolas. Además, los concejales de AD y Copei lucharon contra la propuesta de los gobiernos parroquiales desde el inicio, argumentando que el énfasis en la participación directa de la ciudadanía socavaba la democracia representativa. Cuando Istúriz trató de consolidar los gobiernos parroquiales a través de un decreto debatido y diseñado en asambleas públicas, la oposición luchó contra éste hasta un mes antes de las elecciones de 1995. El decreto fue aprobado en noviembre, la CR perdió las elecciones de diciembre y el recién victorioso $A D$ inmediatamente anuló el decreto.

\section{Montevideo}

Los grupos fuertemente institucionalizados de Uruguay, el Partido Colorado y el Partido Nacional, siempre recibían entre los dos por lo menos el $80 \%$ de los votos hasta el golpe de estado de 1973. A través de su sistema de "coparticipación", se repartían los cargos políticos y administrativos proporcionalmente, llenando las burocracias nacionales y provinciales con sus respectivos simpatizantes. El bastión de los colorados era Montevideo, donde usaban la burocracia como una herramienta para mantener el apoyo político. Con excepciones (1958-1962 y 1983-1984), Ios colorados gobernaron Montevideo consecutivamente desde 1918 hasta 1989. Los colorados fundaron cientos de "clubes políticos" en Montevideo, cada uno con un caudillo vecinal, quien era a su vez un empleado público y un activista político. A través de los clubes, los residentes de los barrios pobres y de clase trabajadora buscaban favores personales y, a veces, la prestación de servicios públicos. Ni siquiera la dictadura interrumpió la dominación del Partido Colorado; el intendente colorado, elegido en 1971, continuó en su cargo hasta el último año de la dictadura. Después de ganar la primera elección post-militar (1984) en Montevideo y a nivel nacional, los colorados reiniciaron sus políticas clientelistas, restableciendo los clubes y creando una nueva oficina que estimuló el crecimiento de asociaciones vecinales por medio de la repartición de cupones de comida.

Cuando el alcalde del FA, Tabaré Vázquez, llegó al poder en 1990, los colorados intentaron usar su influencia sobre las asociaciones vecinales y los trabajadores municipales para obstruir su programa de participación. Las asociaciones simpatizantes de los colorados participaban escasamente, y los burócratas designados por administraciones coloradas anteriores deliberadamente retrasaban los trámites, y empujaron al sindicato municipal al paro. Estos intentos fueron menos exitosos que la campaña unificada de los colorados y blancos (del Partido Nacional) que, por medio de concejales, congresistas, e incluso el presidente Lacalle (blanco) denunció el programa del FA. En más de 150 ataques de la prensa, éstos acusaron al FA de implantar tácticas de la KGB y los Comités de Defensa de la Revolución de Cuba; Lacalle llamó "totalitaria" a la administración del FA (Sierra y Charbonnier, 1993: 18-19, 28). La oposición también bloqueó recursos para la administración municipal del FA, recortando transferencias, rechazando contratos o negando el aumento de impuestos municipales. Once concejales de oposición, valiéndose de la Constitución unitaria de Uruguay, apelaron al Congreso para que invalidara la resolución municipal de Vázquez, que establecía un programa de participación. 
Cuando Vázquez invitó a los concejales para que colaboraran con el diseño de las nuevas instituciones participativas, éstos dilataron las negociaciones durante dos años e insistieron en que los representantes partidistas debían jugar un rol central en cualquier cuerpo con poder de decisión en el ámbito local. Ignorando las preocupaciones expresadas por algunos aliados del FA dentro de la comunidad, Vázquez cedió a las exigencias de la oposición. Como resultado, las reformas en las instituciones participativas limitaron notablemente el poder de decisión de los ciudadanos, y privilegiaron a los actores políticos.

\section{Porto Alegre}

La baja institucionalización de los partidos en Brasil se debió, en parte, a las reglas electorales permisivas que el régimen militar introdujo con el fin de dividir el movimiento democrático. Poco después emergieron docenas de partidos, pero ninguno consiguió hegemonía en Porto Alegre ni en el ámbito nacional. Ocho grupos obtuvieron escaños en la cámara municipal en las elecciones de 1988 y de 1992. Cinco candidatos se postularon a la alcaldía en 1985 y ocho en 1988. En esa década, para cargos ejecutivos a nivel estatal y municipal, ninguno ganó elecciones consecutivas. A pesar de la fragmentación general y la debilidad de los partidos locales, al menos dos de ellos pudieron haber desarrollado lazos sociales duraderos: el PMDB y el PDT (Partido Democrático Trabalhista). El PMDB tenía una historia más larga que otros, pero no tenía una organización a nivel municipal en Porto Alegre. Además, la creación de nuevas agrupaciones durante la década del ochenta debilitó al PMDB, ya que muchos de sus líderes se pasaron a otros, en particular al PDT. El PDT fue fundado por Leonel Brizola, ex-alcalde de Porto Alegre y ex gobernador de Rio Grande do Sul, y el reducto más fuerte de éste fue en Porto Alegre. En la primera elección de alcaldes en 1985, el candidato del PDT, Alceu Collares, ganó fácilmente, y Brizola consiguió un apoyo abrumador en su aspiración presidencial de 1989. Sin embargo, el PDT era principalmente eso: Brizola, Collares, y otros cuantos líderes históricos. EI PDT no logró establecer una fuerte organización.

Al final de la década de los ochenta, ningún partido político en Porto Alegre había conseguido establecer relaciones duraderas con los votantes $u$ organizaciones sociales. A diferencia de Caracas, los sindicatos municipales de Porto Alegre contaron siempre con pluralidad de grupos en sus directivos. Y a diferencia de Caracas y Montevideo, pocas organizaciones vecinales estaban subordinadas a una única organización. Esto no significa que las relaciones clientelistas no existieran. La diferencia con Porto Alegre era que muchas de las organizaciones de estilo clientelista eran oportunistas. Estas establecían relaciones transitorias con políticos y partidos, o permitían la participación de varios partidos, de modo que ninguno tuviera una predominancia. Los líderes de UAMPA, por ejemplo, venían de diferentes conglomerados. Los concejos populares, o grupos informales de coordinación de movimientos a nivel distrital, tenían también directivos multipartidistas.

Cuando el PT implementó el presupuesto participativo, los entes locales de oposición tenían poco que perder a comparación de AD en Caracas o los colorados en Montevideo, y carecían de recursos organizacionales que les permitieran retar de forma efectiva los programas del PT. A diferencia de los otros casos, la oposición en Porto Alegre no presentó una reacción unificada ni uniforme. El PMDB no habló del presupuesto participativo cuando éste comenzó. El PDT estaba 
dividido. Algunos concejales y el ex alcalde Collares trataron de convencer a los miembros del PDT de no participar, particularmente a través de sus aliados en UAMPA. Sin embargo, atacar el PP no fue una prioridad, y los miembros de base no siempre seguían a Collares. Incluso los miembros de las asociaciones afiliadas a UAMPA ignoraron las instrucciones de no participación. Los líderes opositores criticaron la administración petista a través de la prensa, pero se enfocaron en asuntos distintos al PP.

EI PT enfrentó presiones coordinadas por parte de organizaciones comunitarias, especialmente los concejos populares, que condujo a protestas contra la administración petista cuando ésta no cumplía con inversiones prometidas, y presionaron constantemente por cambios en el diseño del presupuesto participativo. La administración accedió a varias demandas de la comunidad: la ampliación del número de distritos para aumentar la participación, la creación de un plan de inversión anual donde se expusieran todos los proyectos y los costos estimados, y diseminar las inversiones entre los distritos y barrios de acuerdo a prioridades locales, necesidades y cantidad de población, en vez de enfocar las inversiones en pocos barrios como vitrinas. El resultado fue un programa participativo más abierto que los de Caracas y Montevideo.

La estructura del PP portoalegrense está basada en dos premisas. Cualquiera puede participar en las asambleas anuales de presupuesto, y aquellos que intervienen tienen el mismo derecho a voz y voto, y a postularse como delegados distritales o en foros temáticos, y posteriormente al consejo de presupuesto municipal. Todas las reuniones en cada nivel están abiertas al público. No hay privilegios para los representantes partidistas. En especial, el poder de los participantes en la toma de decisiones es mucho mayor en Porto Alegre. Por ejemplo, la lista de proyectos prioritarios que arma cada asamblea distrital es respetada por el gobierno. Los participantes de las asambleas eligen y califican estos proyectos, los delegados votan por una lista final, y ni el alcalde ni el consejo de presupuesto pueden modificar estas prioridades. Una clave final en el diseño es que la alcaldía se vale de las deliberaciones de los participantes para asignar el gasto tanto entre los distritos como de los tipos de servicios urbanos prestados. La estructura asequible y el poder de decisión deliberativa del PP de Porto Alegre motivó a los participantes, y en consecuencia fue sólo allí que el nivel de participación aumentó con el tiempo, que comenzó con menos de mil participantes en 1990 hasta llegar a veinte mil en 2000. El diseño abierto de PP también estimuló el crecimiento y democratización de las asociaciones vecinales en Porto Alegre, lo que no ocurrió en Montevideo ni en Caracas.

Un descubrimiento importante al examinar estas tres ciudades es el potencial de los partidos fuertemente institucionalizados para socavar las ventajas de la descentralización para la democracia local, incluso cuando líderes políticos comprometidos llevan a cabo reformas de participación en ciudades con sociedades civiles activas. Por lo tanto, el éxito del PP en Porto Alegre difícilmente puede ser replicado en otro lugar, donde no existan las condiciones apropiadas. Sin embargo, el modelo de Porto Alegre es el que ha estimulado mayor interés en otros países. 


\section{ESTUDIOS DE CASOS NACIONALES: BOLIVIA, BRASIL, GUATEMALA, NICARAGUA Y PERÚ ${ }^{8}$}

Al analizar los estudios de caso por país, en los que los gobiernos locales implementaron el PP por leyes nacionales, los aspectos competitivos deben ser examinados con mayor profundidad. El PP es una institución política que hace parte de una competencia normal entre partidos (Goldfrank y Schneider, 2006). Los líderes políticos estratégicamente introducen e intentan diseñar el PP con múltiples propósitos, incluyendo obtener apoyo electoral, debilitar a los adversarios, formar alianzas, y cumplir con preceptos ideológicos. Como toda nueva institución, los resultados no son necesariamente los que originalmente se esperan. Las consecuencias dependen no sólo de la intención de los diseñadores y de los contextos locales, sino de las intenciones y estrategias de otros actores, incluidos los oponentes políticos. Este punto es especialmente importante al examinar los casos nacionales, dado que los proyectos de políticos en diferentes instancias de gobierno entran en conflicto directo.

La reciente expansión de participación ciudadana en los procesos de presupuesto subnacionales permite una oportunidad para examinar un amplio rango de hipótesis acerca de las condiciones previas, características de diseño y objetivos estratégicos. Antes de examinar estos países por separado, algunas comparaciones generales, basadas en la discusión previa, pueden ser realizadas con respeto a los casos brasileños, sobre los cuales reposa la mayoría de teorías acerca de PP. Cada uno de los países es considerado políticamente descentralizado, dado que las autoridades municipales son elegidas en forma directa. Sin embargo, mientras las autoridades regionales son elegidas en Brasil y Perú, éstas son nombradas en Guatemala, Nicaragua y Bolivia. En estos últimos países, algunos administradores nacionales han concentrado recursos "descentralizados" en gobiernos regionales con el fin de evitar apoyar a los municipios en manos de la oposición. Las experiencias brasileñas tienen otras posibles condiciones previas ventajosas. Como no existen leyes nacionales que exijan la implementación de PP, en las trescientas y tantas ciudades donde se lleva a cabo actualmente, es más probable que los alcaldes estén más comprometidos con la participación ciudadana que sus contrapartes en otros países. Setenta y tres de las 140 ciudades que implementaron el PP durante 1997-2000 tenían alcaldes petistas, y 33 de otros partidos de izquierda. Además, dado que Brasil posee mayores recursos y es más descentralizado que otros países, sus municipios generalmente tienen mayor capacidad de gasto per cápita. La mayoría de ciudades brasileñas pueden destinar entre $\$ 240$ y \$ 400 por habitante (Cabannes, 2004: 32). En los casos centroamericanos y andinos estudiados aquí, los municipios gastan muchísimo menos (tan sólo como \$11 per cápita en algunas ciudades nicaragüenses). Además, la presencia de organizaciones civiles y su capacidad para trabajar en equipo debe ser mayor en los municipios brasileños que en aquellos de Guatemala, Nicaragua y Perú, dadas sus recientes y polarizadas guerras civiles.

La única condición previa que algunos autores esperan beneficie los casos no brasileños es su origen legal. Mientras las leyes brasileñas requieren la creación de consejos municipales para salud y educación en las grandes ciudades, éstas no requieren consejos de presupuesto. Las leyes nacionales en los otros cuatro países exigen consejos locales con responsabilidades en la 
creación del presupuesto y en el monitoreo de su implementación. Las leyes de Perú van más allá. Como se mencionó, Toledo implementó el presupuesto participativo en 2003. Las leyes de Guatemala con respecto a este tema son contradictorias. Las otras dos condiciones restantes -personal competente y tamaño reducido-varían entre y dentro de los países. Estas condiciones se compensan la una a la otra, en el sentido de que las grandes ciudades, que tienden a tener pocos índices de participación en varias actividades cívicas locales, tratan, por otra parte, de tener un personal profesional más competente.

En relación con el diseño institucional, los casos brasileños ofrecen un claro contraste con respecto a los de los otros países. Primero, aunque las experiencias de PP generalmente están más enfocadas en necesidades inmediatas que en planeación a largo plazo, esto es más evidente en los casos brasileños. Segundo, la estructura del PP es menos formal en las ciudades brasileñas que en otros lugares. Como anota Cabannes (2004: 36), mientras el PP brasileño generalmente busca la participación individual: "Otras ciudades latinoamericanas tienden a favorecer la participación a través de representantes de organizaciones existentes". Cabannes (2004: 40) también señala que mientras que en la mayoría de ciudades brasileñas el PP se regula de forma interna, fuera de Brasil, "el PP ha sido regulado e institucionalizado por resoluciones municipales, decretos, leyes o constituciones". Tercero, el PP brasileño es claramente deliberativo, con asambleas comunales que discuten y deciden las prioridades de inversión en términos anuales, y se dan foros regionales o temáticos, donde delegados se reúnen durante el año para negociar los detalles de presupuesto con autoridades de la ciudad, antes de enviarlo a la cámara municipal para su aprobación. En otros países, el carácter deliberativo del PP es difícil de constatar. Las leyes de Bolivia, Guatemala y Nicaragua sugieren más un rol de consulta para los consejos de desarrollo, y en el PP peruano la ley exige que el $60 \%$ de los miembros del consejo de coordinación sean autoridades gubernamentales. Aproximadamente la mitad de los miembros de los consejos de desarrollo en Guatemala y Nicaragua forman parte del gobierno. Además, mientras la alcaldía generalmente está a cargo del PP en las distintas experiencias latinoamericanas, el acceso a las reglas y a la información tiende a ser mucho mayor en las experiencias brasileñas. En parte, esto tiene que ver con la mayor cantidad de recursos disponibles para los municipios brasileños, lo que les permite imprimir folletos con las reglas y publicitar las reuniones.

¿De qué manera las condiciones previas y los diseños han afectado los resultados de PP en las experiencias de Bolivia, Guatemala, Nicaragua y Perú comparadas con aquellas de Brasil? En general, mientras los análisis de PP en Brasil reportan muchos más casos de éxito en un amplio rango de indicadores, los observadores de las experiencias no brasileñas son menos optimistas. La implementación de leyes nacionales sobre la participación ciudadana en procesos de presupuestos subnacionales ha sido lenta y desigual en cada uno de los cuatro países. Esto parece reflejar la indiferencia u hostilidad hacia el PP por parte de muchos alcaldes, y la falta de personal calificado en muchos de los gobiernos municipales, especialmente en los pequeños. En cuanto a la composición de los consejos de desarrollo, las autoridades regionales y locales regularmente se han valido de procedimientos poco democráticos, lo que alimenta la apreciación generalizada de que el clientelismo y la corrupción continúan sin resolverse. La falta de criterios claros ha contribuido a una distribución de recursos sesgada hacia los centros urbanos, incluso en áreas predominantemente rurales, que socava los intentos de reducción de la pobreza. Los índices de participación ciudadana han sido bajos también. Por otra parte, para Brasil, algunos académicos 
han expresado inquietud de que el PP allí no logra convertirse en una planificación urbana efectiva a largo plazo, genera antagonismo con las cámaras municipales y no es legalmente requerido en todos los 5.507 municipios.

Las divergencias reportadas en esta amplia comparación regional sugieren que los observadores han identificado correctamente varias condiciones previas y características de diseño importantes. La voluntad política, la competencia del personal, los recursos suficientes y un diseño informal, deliberativo y basado en reglas y necesidades, son características que parecen estar relacionadas con mayores probabilidades de PP exitoso. Además, las condiciones previas, los objetivos estratégicos y el diseño institucional también parecen estar relacionados entre sí. Donde los gobiernos nacionales intentan fomentar la participación a través de legislación, éstos tienden a crear instituciones demasiado formales que privilegian organizaciones políticas y sociales ya existentes, en vez de crear procesos abiertos y deliberativos ${ }^{9}$. La cuestión de cuáles organizaciones son las favorecidas depende de las metas de quiénes ostentan el poder a nivel nacional y local. Los procesos de PP creados en el ámbito local tienden a ser más informales y deliberativos, probablemente por dos razones. Una es que los alcaldes que implementan el PP responden a peticiones de movimientos sociales para la creación de espacios públicos de deliberación, y la otra es que los formatos abiertos permiten a los alcaldes atraer a nuevos electores. Probablemente no es coincidencia que la mayoría de casos de PP exitosos en Perú tengan (1) diseños más informales y deliberativos, y (2) hayan sido impulsados por alcaldes antes de la ley de 2003. Una mirada más cercana a las experiencias de Bolivia, Guatemala, Nicaragua y Perú confirma estas conclusiones.

\section{Bolivia}

Desde que el Presidente Sánchez de Losada introdujo la Ley de Participación Popular (LPP) en 1994, junto con otras medidas de descentralización, la experiencia de participación ciudadana en el presupuesto local ha tenido resultados mixtos. Mientras muchos observadores encuentran fallas tanto en el diseño de las instituciones participativas, y cómo éstas han funcionado en la práctica, con una participación limitada y poco significativa en la mayoría de municipios, algunos ven mejoras concretas en los estándares de vida de las comunidades rurales ${ }^{10}$. Es probable que cualquier mejora se haya debido más al aumento de los fondos disponibles para los municipios que al incremento de la participación ciudadana. Los recursos de transferencias para todos los gobiernos locales fue más que el triple desde 1993 a 1997, y excluyendo las capitales regionales, las trasferencias pasaron de cerca de \$ 4 millones por año a aproximadamente \$112 millones (Altman, 2003: 77). Esto fue antes de la adición de fondos de HIPC II en 2000. En relación con las fallas de participación, Bolivia presenta un claro ejemplo de incertidumbre asociado con la creación de nuevas instituciones, en el cual las diseñadas a nivel nacional fueron modificadas (o rechazadas) por autoridades locales y de acuerdo a condiciones locales.

Las motivaciones de Sánchez de Losada para implementar la LPP son fuente de debate. Muchos analistas sugieren que, además de los ideales democráticos, reducción de la pobreza y reforzar el programa de ajuste estructural de la década anterior, un número de puntos estratégicos fue 
determinante especialmente en el diseño de la LPP. Primero, porque su partido era más débil en las capitales departamentales, y porque él temía que el deseo de las elites en el departamento de Santa Cruz pudiera crear desunión nacional; las leyes de participación y descentralización pusieron énfasis en los niveles de gobierno municipales más que en los departamentales. El siguiente presidente, Banzer, cuyo partido controlaba las capitales departamentales, revirtió esa tendencia (Altman, 2003: 69). Segundo, las instituciones participativas bajo Sánchez de Losada parecían enfocadas a frenar los sindicatos izquierdistas de obreros y campesinos, los comités cívicos de la elite y los partidos políticos, y quizás construir una alianza con los movimientos indígenas. Por una parte, nombró a un líder indígena como su vicepresidente. Por otra, la LPP dio derecho en la participación y planeación municipal sólo a las organizaciones territoriales de base (OTB), que fueron concebidas como organizaciones comunitarias campesinas e indígenas en las áreas rurales, y como asociaciones vecinales en las áreas urbanas. Se suponía que las OTB usarían costumbres tradicionales en la elección de los comités de vigilancia (CV), encargados de monitorear la implementación del presupuesto en cada municipio. En consecuencia, la LPP ignoró a los sindicatos y a los comités cívicos, y creó un competidor para los representantes partidistas en las cámaras municipales.

Por lo tanto, no es sorprendente que las principales confederaciones obreras (relacionadas con Evo Morales y Felipe Quispe), los comités cívicos, las elites departamentales y los partidos de oposición se opusieran a la LPP (Altman, 2003: 73). Los sindicatos llamaron a la LPP la "ley maldita" y exhortaron a los indígenas campesinos a no participar, aunque esto no fue siempre atendido. Parece que la LPP ha funcionado más efectivamente en comunidades indígenas pequeñas y homogéneas con organizaciones tradicionales fuertes. Sin embargo, en muchos municipios los oponentes a la LPP también obstaculizaron, dilataron y trataron de trastornar las nuevas instituciones participativas. En el primer año después de la LPP, las elites locales manipularon la ley para adaptarla a sus propios intereses, designando miembros en los CV en vez de elegirlos a través de procesos participativos, y otras veces creando OTB ficticias, en vez de trabajar con organizaciones existentes. Aunque la LPP estipulaba que los gobiernos municipales debían contar con mesas de trabajo y consultas para escuchar las demandas de la comunidad, esto no ha ocurrido sistemática o democráticamente en los 327 municipios. Como Bartholdson et al. (2002: 28) sostienen, los partidos políticos "dividieron a los miembros de las comunidades indígenas y locales" usando tácticas clientelistas tradicionales: "particularmente en las tierras bajas bolivianas, los municipios han sido controlados por elites de los centros urbanos y las necesidades de las poblaciones indígenas rurales han sido marginadas".

La manipulación política de las nuevas instituciones participativas ha tenido efectos negativos sobre la colaboración ciudadana en los presupuestos municipales. En muchos municipios, los OTB y CV no funcionan o no son efectivos en cuanto a reflejar las demandas de la comunidad en los presupuestos o al monitorear la ejecución del presupuesto (Altman, 2003: 83-85; Bartholdson, 2002: 29, 47). Parecen faltar canales para la participación directa de los miembros de las comunidades, y la representatividad de las OTB ha sido cuestionada.

Aun así, al menos uno de los aspectos de la LPP parece promover sin ambigüedades la democracia. En el único país suramericano de mayoría indígena, que tiene una larga historia de exclusión de esta mayoría, la LPP está directamente relacionada con el ascenso de alcaldes, concejales y, en consecuencia, líderes nacionales indígenas. Es doblemente irónico que, mientras Sánchez de 
Losada pudo haber impulsado la LPP como una forma de ganar apoyo indígena, los líderes de los movimientos indígenas, quienes criticaron a la LPP, terminaron siendo los más beneficiados por esta ley y eventualmente usaron su creciente fuerza para forzar la salida de Sánchez de Losada de la presidencia.

\section{Guatemala}

Comparada con Bolivia, menos controversia política ha acompañado las leyes de descentralización y de participación en Guatemala. Las reformas en este país fueron iniciadas con los procesos de paz en los noventa, provocaron poca resistencia y fueron promovidas por organizaciones internacionales. Sin embargo, de los países estudiados aquí, Guatemala es el que menos éxitos ha alcanzado con el PP. La mayoría de estudios coinciden en que la participación ciudadana en las decisiones presupuestarias es parte del discurso gubernamental y de ONG, pero que no existe en la práctica. Una serie de problemas impidió el efectivo funcionamiento del PP en Guatemala, empezando con el desinterés por parte de los líderes nacionales, que parecían haber adoptado las leyes de participación por una presión internacional. Aunque la descentralización fiscal se ha incrementado recientemente con la disponibilidad de los fondos de HIPC II, los municipios guatemaltecos continúan siendo relativamente pobres, dependientes de transferencias nacionales poco transparentes y altamente endeudados. Han sido los gobiernos departamentales, con sus líderes nombrados, quienes han recibido la mayor parte de los fondos de inversión, y han podido retener recursos destinados a municipios donde el alcalde elegido toma parte de la oposición (Puente y Linares, 2004: 245-246; 248). Los gobiernos municipales también carecen de personal calificado, y en cuanto a los ciudadanos locales los observadores han notado una falta de interés en los nuevos consejos de desarrollo, y la ausencia de organizaciones civiles, o competencia y división entre aquellas existentes (Centro, 2005: 12).

Posiblemente la principal razón para el fracaso del PP en Guatemala ha sido la ausencia de alcaldes con la voluntad de compartir el poder con la ciudadanía. Desde 1999, entre un tercio y la mitad de los alcaldes han representado al Frente Republicano Guatemalteco, el partido del ex dictador militar Ríos Montt. En los escasos municipios donde los consejos de desarrollo realmente existen, los alcaldes frecuentemente los utilizan para su beneficio político. Se supone que los consejos comunitarios de desarrollo deben estar compuestos por representantes elegidos de forma abierta, en asambleas públicas, lo que generalmente no ocurre en la práctica; por el contrario, los alcaldes eligen sólo a ciertos grupos para que sean representados. Parece ser que los municipios donde los alcaldes son de los comités cívicos, que son locales e independientes, están más comprometidos con el PP. Un caso notable es el de Quetzaltenango, una de las cuatro ciudades más grandes del país. Los comités cívicos ganaron en 25 municipios en 2003 (aunque no en Quetzaltenango), que es menos que un $10 \%$ del total y el mismo número que obtuvieron en 1999. El éxito futuro del PP en Guatemala puede depender, en parte, si los comités cívicos consiguen popularidad en más municipios.

\section{Nicaragua}

A primera vista, Nicaragua al final de los años noventa podría parecer un lugar adecuado para la introducción de PP. Un partido de izquierda con un compromiso retórico con la democracia 
participativa y una historia de alianzas con organizaciones sociales -el Frente Sandinista por la Liberación Nacional (FSLN)- controlaba un tercio de los municipios. El nuevo presidente, Alemán, había sido alcalde de la capital, y las agencias internacionales se habían comprometido con el envío de importantes cantidades de ayuda al país después del huracán Mitch, que fue seguido por los fondos de HIPC II. En 1997, 2000 y 2001, Alemán introdujo reformas de descentralización y participación, desarrolladas, en parte, sobre las leyes de autonomía municipal del FSLN de finales de los ochenta y estimuladas por donantes internacionales. En conjunto, estas leyes obligaban a los gobiernos municipales a consultar con los ciudadanos los presupuestos a través de cabildos abiertos y comités de desarrollo vecinales y municipales. Sin embargo, la voluntad política de los alcaldes para compartir el poder en cuanto la toma de decisiones, el uso honesto y transparente de los fondos internacionales y la aplicación de las reformas, han sido cuestionados.

Incluso algunos observadores que simpatizan con el FSLN no consideran que éste se haya renovado en la misma línea que otros partidos latinoamericanos de izquierda. En cambio, ellos argumentan que el FSLN continuó con tendencias a coaccionar y controlar movimientos sociales aliados, además de cerrar espacios por opiniones disidentes, en vez de promover significativos procesos de participación (Hoyt, 1997). Al mismo tiempo, Alemán tenía una reputación de corrupto mientras fue alcalde de Managua, y posteriormente fue condenado por lavado de activos y malversación de fondos, entre otros cargos, después de supuestamente robar más de \$100 millones de las arcas del gobierno central. Las reformas legales de Alemán fueron acordados con el FSLN como parte de un pacto de gobierno, que también tuvo dos problemas principales. Uno fue que éste incluía medidas que fortalecían el sistema de dominación de dos partidos: el FSLN y la Alianza Liberal de Alemán. El otro fue que estas reformas no estaban acompañadas de los recursos adecuados. Desde 1997 a 2003, las transferencias del gobierno central a los municipios representaban cerca del 1\% del presupuesto gubernamental. En 2004 estas transferencias se incrementaron en un $4 \%$, y se supone que debían crecer en un $1 \%$ anual durante los siguientes seis años, en parte, dependiendo del comportamiento económico del país (Pineda, 2003: 4, 9). Es dudoso que estos incrementos fueran suficientes. Los gobiernos municipales de Nicaragua no cuentan con fondos suficientes, con algunos recibiendo menos de $\$ 9.000$ por año por transferencias del gobierno central, y muchos llevados a la bancarrota. Además, las transferencias estaban condicionadas por criterios políticos, en detrimento de aquellos municipios sandinistas (Howard, 2002).

A la falta de compromiso con un gobierno participativo y la carencia de recursos necesarios, se pueden añadir el clima de polarización política y el poco competente personal municipal a la lista de factores que afectaron al PP. Como en Guatemala, el fracaso para lograr prácticas exitosas en Nicaragua parece sobredeterminado. Mientras las leyes que estimulan la participación parecen valer la pena en el papel, de acuerdo con Pineda (2003: 17): "En la práctica, la asistencia y diálogo en los cabildos no son constantes ni masivos, como el uso de otros procedimientos establecidos...". Otros observadores también señalan que los cabildos abiertos son escasamente atendidos, caóticos e improductivos (Ortega Hegg, 2003: 265-274), mientras que los comités de desarrollo tienden a ser convocados por invitación del alcalde y son, por lo tanto excluyentes, pues sólo favorecen los aliados sociales del alcalde (Howard, 2002). 


\section{Perú}

Como política nacional, el PP de Perú es aún emergente, aunque varios gobiernos locales implementaron el PP por su cuenta antes de las leyes de 2003. Mientras Perú comparte un modelo vertical con otros países estudiados aquí, los diseñadores de las leyes de PP en Perú tuvieron en cuenta las experiencias locales. Esto se puede deber a que algunos miembros del partido gobernante, Perú Posible, venían de las filas de la Izquierda Unida, con una historia de programas de participación municipal en los años ochenta, antes de la década centralista y autoritaria de Fujimori. Un deseo general por la descentralización emergió dentro de la oposición a Fujimori, y agencias internacionales también la promovieron. Por lo tanto, la mayoría de reformas descentralizadoras fueron acordadas fácilmente. Sin embargo, las leyes de participación fueron impugnadas por varios congresistas, y casi no fueron aprobadas (Chirinos, 2004: 192-193, 104106). Haciendo eco de la aproximación conservadora al PP, muchos de los partidos tradicionales, especialmente el Partido Aprista, sostuvieron que los consejos locales de coordinación (CCL), que tendrían funciones de planificación y presupuesto, socavaban la democracia representativa. No es sorpresa que apristas controlen casi la mitad de las 25 gobiernos regionales. El gobierno nacional terminó comprometiéndose con un proyecto de ley híbrido a mediados de 2003 , que le daba a las autoridades locales un $60 \%$ de las sillas en los CCL.

Las leyes de PP obligaban a los gobiernos regionales, provinciales y municipales a promover la participación ciudadana en la formulación, el debate y la concertación de sus planes de desarrollo y presupuestos por medio de los CCL y asambleas públicas. Los observadores encuentran que el PP en los dos primeros años fue poco exitoso en cuanto a la promoción de la participación, la transparencia, la planeación efectiva y la mejora en la infraestructura pública y la prestación de servicios (Chirinos, 2004; Díaz, 2004). Ellos señalan un grupo de factores que afectan negativamente al PP, desde problemas en el diseño hasta resistencia y manipulación por parte de la oposición, recursos insuficientes y la falta de iniciativa de la sociedad civil.

A diferencia de las leyes bolivianas relativamente similares, en Perú todas las organizaciones sociales registradas legalmente, con al menos tres años de existencia, podían participar en elecciones para los CCL. Estas restricciones tenían como fin impedir la creación de organizaciones fantasmas, pero en la práctica excluyeron a muchas organizaciones de los pobres, que carecían de registro legal. Además, los representantes de la sociedad civil sólo tenían acceso a un 40\% de las sillas en los consejos, y un tercio de aquellas estaba reservado para representantes empresariales, lo que también tendía a minimizar la participación de los pobres. Otro problema fue que había contradicciones entre la ley y los lineamientos del Ministerio de Economía y Finanzas. Como sucedió en otros casos de PP implementados por legislación nacional, muchos líderes locales y regionales simplemente decidieron ignorar las reglas.

En efecto, a mediados de 2004, sólo un tercio de los 1.821 municipios distritales había creado CCL (Díaz, 2004: 225). La mayoría de alcaldes parece haber acatado "la formación de los CCL más por razones formales que por convicciones democráticas", dado que éstos no asumieron los roles de planeación y de presupuesto contemplados en la ley (Díaz, 2004: 233-234). El Congreso tuvo que promulgar leyes adicionales con el fin de forzar a los gobiernos regionales para que establecieran los consejos de coordinación y después estos fueron escasamente convocados. Además, las elecciones para los consejos nunca se dieron o fueron poco democráticas; generalmente 
las autoridades locales invitaban a organizaciones específicas para elegir a los representantes (Díaz, 2004: 227-228; Chirinos, 2004: 1995, 210).

Incluso donde los alcaldes estaban comprometidos con el PP, permanecían los problemas de extrema dependencia sobre transferencias escasas y poco fiables del gobierno central, y una sociedad civil fragmentada con poco interés en la participación institucionalizada, que además no contaba con suficiente información acerca de las leyes promulgadas. En general, los municipios peruanos dependen de las transferencias, que en 2004 alcanzaron casi el $4 \%$ del presupuesto nacional, y se estima que se incrementarán a un 12\% para 2006 (Schneider y Zuniga-Hamlin, 2005: 17). Dividido entre 2.000 presupuestos municipales, esto se traduce en muy poco. Además, para recibir transferencias de los fondos de inversión, los municipios tienen que seguir normas estrictas y poco publicitadas. Varios gobiernos regionales y locales han tenido que devolver recursos al gobierno central por no cumplir con estas normas. Al mismo tiempo, para Díaz (2004: 234-236), los ciudadanos muestran poco nivel de organización, las organizaciones carecen de formalización, y los delegados de las organizaciones no son representativos ni calificados, y están divididos.

Un punto que se puede resaltar en el caso peruano es que el Ministerio de Economía y Finanzas revisa los lineamientos de PP cada año, al parecer, en respuesta a las críticas hechas por parte de alcaldes, gobernadores y organizaciones cívicas. Los cambios en 2005 parecen haber corregido algunos problemas de diseño, por enfatizar que los presupuestos acordados en los consejos de coordinación deben ser respetados por las autoridades municipales y establecer que el proceso de PP debe estar abierto a todos aquellos que quieran participar.

\section{CONCLUSIONES}

La perspectiva comparada adoptada por este trabajo pareciera llevar a conclusiones pesimistas sobre las posibilidades de reproducir el éxito que ha tenido el PP en numerosas ciudades brasileñas, y, sobre todo, en Porto Alegre. Sin embargo, no todas las conclusiones apuntan en esa dirección. Los tres puntos principales de esta última sección regresan a las aproximaciones normativas para examinar el futuro del PP.

Primero, ninguna de las interpretaciones captura la amplia variedad de los diseños y los resultados del PP. Éste no siempre fortalece al estado contra el mercado, como sueña la nueva izquierda y temen los conservadores que ni protege, necesariamente, las reformas del mercado, como esperan los liberales y temen los ortodoxos. Su adopción por partidos pro mercado del centro y de la derecha, tanto en Brasil como en otros países, presenta un desafío al primer argumento, y las protestas recurrentes contra la privatización en países como Bolivia, Nicaragua y Perú socavan el segundo argumento. Aun dentro de un mismo país, la variedad de los resultados del PP es asombrosa. A pesar de su aparente falta de éxito generalizado en estos países, hay numerosas experiencias locales con resultados impresionantes en términos del mejoramiento de la transparencia, reactivación de la sociedad civil y de la participación, y de la expansión de los servicios públicos hacia sectores hasta entonces excluidos (Goldfrank, por aparecer). Estos logros han ocurrido en lugares muy diversos, desde pequeños pueblos rurales e indígenas 
muy pobres hasta ciudades grandes con poblaciones de diferentes clases sociales y grupos étnicos. El éxito está correlacionado con varios factores en diferentes combinaciones: el alcalde está especialmente comprometido con el proceso por razones ideológicas, la oposición de la elite política es débil, hay organizaciones de ayuda que brindan apoyo financiero o técnico al municipio que tiene recursos suficientes para hacer inversiones significativas, y hay una tradición de colaboración entre las asociaciones civiles que no ha sido destruida por clientelismo o guerras civiles.

Segundo, las batallas interpretativas a cerca del PP siguen en el presente y probablemente perdurarán. Por un lado, las agencias y bancos de desarrollo internacional con una perspectiva liberal están promoviéndolos en muchos más países y con más énfasis que nunca. Hoy día se pueden encontrar agencias internacionales abogando por el PP, y gobiernos locales implementando a éste desde Albania hasta Zambia. Por otro lado, tiene viejos y nuevos admiradores en la izquierda latinoamericana, desde sectores del Partido de los Trabajadores y del Frente Amplio que están clamando por procesos nacionales del PP en Brasil y Uruguay, hasta Hugo Chávez en Venezuela. En Venezuela, la participación ciudadana en consejos locales de planificación y presupuesto está contemplada en los artículos 168, 182, y 184 de la nueva Constitución "bolivariana" (Nunes, 2004: 130, 137), la cual fue escrita con la ayuda del ex acalde de Caracas, Istúriz, quien actuó como vicepresidente de la Asamblea Constituyente. De hecho, muchos ex miembros de la Causa R fundaron un nuevo partido, Patria Para Todos, y ahora están en el gobierno con Chávez, quien, además, está exhortando a sus correligionarios que adopten el PP en sus municipios y estados.

Tercero, dentro de esta lucha para definir, proponer, e implementar el PP, la aproximación liberal está en ascendencia. A medida que éste se ha extendido fuera de las ciudades brasileñas, el diseño abierto, informal y deliberativo iniciado por la nueva izquierda en Porto Alegre parece estar pasando de moda. En su reemplazo han aparecido diseños más regulados, formales y consultivos enfocados en organizaciones ciudadanas existentes, como los implementados en Bolivia, Nicaragua y Perú con una perspectiva más liberal. Esta tendencia puede ser observada incluso dentro de Brasil, donde habían algunas esperanzas de que Lula implementaría el PP en el ámbito nacional. El mayor intento participativo de Lula fue una serie de reuniones para definir el presupuesto federal plurianual, que tuvieron lugar en los veintisiete Estados. En cada reunión el gobierno invitó a setenta ONG. Este proceso, así como en general el gobierno de Lula, ha sido criticado por confederaciones de ONG por no proveer espacios de deliberación abiertos y participativos (Goldfrank y Schneider, 2006). Además, en Porto Alegre, la ciudad con la experiencia de PP más reconocida, el Partido de los Trabajadores perdió en 2004 las elecciones municipales después de cuatro victorias consecutivas. Aunque el nuevo alcalde había prometido mantener el PP, su administración parece estar restándole importancia mientras desarrolla un nuevo concepto de "gobernanza solidaria local" que se fundamenta más en las organizaciones profesionales y empresariales. Si los nuevos gobiernos de izquierda que actualmente están accediendo al poder en Latinoamérica no son fuertemente presionados para implementar el PP en su forma original, es probable que en el futuro sean las aproximaciones liberales las que predominen. 


\section{REFERENCIAS}

Abers, Rebecca. 1996. "From Ideas to Practice: The Partido dos Trabalhadores and Participatory Governance in Brazil". Latin American Perspectives 23 (4): 35-53. 2000. Inventing Local Democracy. Boulder: Lynne Rienner.

Altman, David y Rickard Lalander. 2003. "Bolivia”s Popular Participation Law: An Undemocratic Democratisation Process?”. En Decentralisation and Democratic Governance: Experiences from India, Bolivia and South Africa, editado por Axel Hadenius. Stockholm: Expert Group on Development Issues, 63-103.

Baierle, Sérgio. 2003. "The Porto Alegre Thermidor? Brazil"s “Participatory Budget" at the Crossroads". Socialist Register: 300-322.

Baiocchi, Gianpaolo. 2001. "Participation, Activism, and Politics: The Porto Alegre Experiment and Deliberative Democratic Theory”. Politics \& Society 29 (1): 43-72.

Bartholdson, Örjan et al. 2002. Popular Participation in Bolivia, Colombia and Peru: A Synthesis of Three Studies. Stockholm: Swedish International Development Cooperation Agency en http://www.kus.uu.se/SAdelstudie.pdf

Cabannes, Yves. 2004. "Participatory Budgeting: A Significant Contribution to Participatory Democracy". Environment \& Urbanization 16 (1): 27-46.

Campbell, Tim. 2003. The Quiet Revolution: Decentralization and the Rise of Political Participation in Latin American Cities. Pittsburgh: University of Pittsburgh Press.

Centro Pluricultural para la Democracia. 2005. "Presupuesto participativo: reflexiones y propuestas en el ámbito municipal". Quetzaltenago (March) en http://www.cpdguatemala.org/DoctoPresupuestoParticipativo.pdf

Chirinos Segura, Luis. 2004. "Participación ciudadana en gobiernos regionales: el caso de los Consejos de Coordinación Regional”. En La participación ciudadana y la construcción de la democracia en América Latina, editado por Grupo Propuesta Ciudadana. Lima: Ser, Consode, Oxfam, Grupo Propuesta Ciudadana, Participa Perú, DFID, EED, y USAIDPeru, 189-222.

Coppedge, Michael. 1994. Strong Parties and Lame Ducks. Stanford: Stanford University.

De Sierra, Gerónimo y Blanca Charbonnier. 1993. "Descentralización y participación”. En Participación ciudadana y relaciones de gobierno, editado por CIEDUR-CIESU-ICP-FESUR. Montevideo: Trilce, 1-20.

Díaz Palacios, Julio. 2004. "Los Consejos de Coordinación Local”. En La participación ciudadana, editado por Grupo Propuesta Ciudadana. Lima: Ser, Consode, Oxfam, Grupo Propuesta Ciudadana, Participa Perú, DFID, EED, y USAIDPerú, 223-238.

Dutra, Olívio. 2002. "El Presupuesto Participativo y la cuestión del socialismo". En http: //www.cta.org.ar/docs/prespart/ PPysocialismo.doc

Evans, Peter. 2004. "Development as Institutional Change: The Pitfalls of Monocropping and the Potentials of Deliberation". Studies in Comparative International Development 38 (4): 30-52.

Fox, Jonathan. 1995. "The Crucible of Local Politics". NACLA: Report on the Americas 29 (1): 15-19.

Fung, Archon y Erik Olin Wright. 2001. "Deepening Democracy: Innovations in Empowered Participatory Governance". Politics \& Society 29 (1): 5-41.

Goldfrank, Benjamin. 2002. Urban Experiments in Citizen Participation: Deepening Democracy in Latin America. Tesis Doctoral, Ciencia Política, University of California, Berkeley.

2005. "The Politics of Deepening Local Democracy: Decentralization, Party Institutionalization, and Participation". Ponencia presentada en American Political Science Association Conference, Washington, DC, September.

Por aparecer. "Lessons from Latin American Experience in Participatory Budgeting". En Participatory Budgeting, editado por Anwar Shah. Washington, DC: WBI.

y Aaron Schneider. 2006. “Construcción institucional competitiva: el PT y el Presupuesto Participativo de Rio Grande do Sul”. En Diseño institucional y participación política: experiencias en el Brasil contemporáneo, editado por Catia Lubambo, Denilson Coêlho y Marcus Melo. Buenos Aires: CLACSO, 253-291.

Harnecker, Marta. 1995. Caracas: La alcaldía donde se juega la esperanza. Havana, Caracas: MEPLA-Fundarte.

Howard, Joanna. 2002. “Write Ups on Esteli’s Participatory Planning Initiative”. En http://www.ids.ac.uk/ logolink/resources/ downloads/PPcase_studies/Nicaragua-Esteli1.doc

Hoyt, Katherine. 1997. The Many Faces of Sandinista Democracy. Athens, OH: Ohio University Center for International Studies.

Huntington, Samuel. 1968. Political Order in Changing Societies. New Haven: Yale University.

Kreuzer, Marcus y Vello Pettai. 2004. "Political Parties and the Study of Political Development". World Politics 56 (July): 608-633.

Marquetti, Adalmir. 2002. "Democracia, Eqüidade e Eficiência: o Caso do Orçamento Participativo em Porto Alegre". En Construindo um Novo Mundo: Avaliação da experiência do Orçamento Participativo em Porto Alegre-Brasil, editado por João Verle y Luciano Brunet. Porto Alegre: Guayí, 210-232. 
Mascareño, Carlos. 2000. Balance de la Descentralización en Venezuela. Caracas: PNUD-Ildis-Nueva Sociedad.

Montero, Alfred. 2000. "Devolving Democracy? Political Decentralization and the New Brazilian Federalism”. En Democratic Brazil, editado por Peter Kingstone y Timothy Power. Pittsburgh: University of Pittsburgh, 58-76.

Nunes, Luis. 2004. "Participación ciudadana y construcción de la democracia en América Latina: El caso Venezuela”. En La participación ciudadana y la construcción de la democracia en América Latina, editado por Grupo Propuesta Ciudadana. Lima: Ser, Consode, Oxfam, Grupo Propuesta Ciudadana, Participa Perú, DFID, EED, y USAID-Perú, 119-142.

Nylen, William. 2003. Participatory Democracy versus Elitist Democracy: Lessons from Brazil. New York: Palgrave Macmillan.

Ortega Hegg, Manuel. 2003. "La conversion de un "canal formal” en un "espacio real” de participación social”. En Participación ciudadana y desarrollo Local en Centroamérica, editado por Ricardo Córdova et al. San Salvador: FUNDAUNGO, 265-274.

Pineda Gadea, Claudia. 2003. Condiciones del Marco Nacional para los Procesos de Preparación Participativa de Presupuestos Municipales en Nicaragua. Managua: WBI.

Portillo, Álvaro. 1996. Montevideo: la ciudad de la gente. Montevideo: Nordan-Comunidad.

Puente Alcaraz, Jesús, y Luis Felipe Linares López. 2004. "A General View of The Institutional State of Decentralization in Guatemala". En Decentralization and Democratic Governance in Latin America, editado por Joseph Tulchin y Andrew Selee. Washington, DC: Woodrow Wilson Center, 231-272.

Schabbach, Leticia. 1995. Práticas e Representações de Funcionários Públicos. Tesis de Maestría, Sociologia, UFRGS.

Schneider, Aaron y Rebecca Zúñiga-Hamlin. 2005. "A Strategic Appproach to Rights: Lessons from Clientelism in Rural Peru”. Development Policy Review 23 (5): 567-584.

Sousa Santos, Boaventura de. 1998. "Participatory Budgeting in Porto Alegre: Toward a Redistributive Democracy". Politics \& Society 26 (4): 461-510.

Souza, Celina. 2001. "Participatory Budgeting in Brazilian Cities: Limits and Possibilities in Building Democratic Institutions". Environment \& Urbanization 13 (1): 159-184.

Wampler, Brian. 2004. "Expanding Accountability Through Participatory Institutions: Mayors, Citizens, and Budgeting in Three Brazilian Municipalities”. Latin American Politics \& Society 46 (2): 73-99.

y Leonardo Avritzer. 2004. "Participatory Publics: Civil Society and New Institutions in Democratic Brazil". Comparative Politics 36 (3): 291-312.

Benjamin Goldfrank es Profesor Asistente de Ciencia Política en la Universidad de Nuevo México. Su doctorado en Ciencia Política es de la Universidad de California, Berkeley. Su enfoque es el análisis comparativo de la política latinoamericana, los gobiernos locales y la participación ciudadana. Él es el co organizador de un libro, La izquierda en la ciudad: Participación en los gobiernos locales de América Latina (Barcelona: Icaria y Transnational Institute, 2004), disponible también en inglés e italiano, y es autor de artículos en revistas académicas como Politics \& Society, Latin American Politics and Society, y Comparative Politics (por aparecer).

(E-mail: goldfran@unm.edu) 